We must conclude, therefore, that at low temperatures either the energy distribution of neutrons in the $C$ group is not given by Maxwell's law or the $1 / v$ law does not hold for the absorption of $C$ neutrons in silver, using the second period as detector.

V. FOMIN.

F. G. Houtermans.

I. W. KuRtshatov.

A. I. LetPUNSKI.

L. Shubnikov.

G. SHTSHEPKIN.

Ukrainian Physico-Technical Institute,

Kharkov.

June 18.

${ }^{1}$ E. Amaldi and E. Fermi, Ricerc. Scient., ser. II, 7, vol. 1, No 11-12. See also F. Rasetti and G. A. Fink, Phys. Rev., 49, 642 (1936) and P. N. Powers, G. A. Fink and G. A. Pegram, Phys. Rev., 49,

\section{Cross Linkage Formation in Keratins}

OwING to the breakdown of salt and sulphur linkages, and consequent rearrangement of the peptide chains, untreated wool fibres contract 30 per cent in length in boiling sodium bisulphite solution, whereas fibres containing stable linkages between the peptide chains fail to contract under similar conditions ${ }^{1}$. This fact has been used to show that baryta-treated fibres contain - S- $-\mathrm{Ba}-\mathrm{S}-$ bonds $^{2}$, and set fibres contain - $-\mathrm{S}-\mathrm{NH}-$ bonds $^{3}$ between the peptide chains. In addition, since caustic soda-treated fibres fail to contract in sodium bisulphite solution, it was suggested that $-\stackrel{+}{\mathrm{C}}-\mathrm{S}-\stackrel{\mathrm{C}}{\mathrm{C}}-$ bonds are formed by the action of caustic soda on the cystine linkage, thus explaining why skins are more difficult to unhair after treatment with alkali ${ }^{4}$. In support of this view, it was pointed out that Harris had failed to reduce the sulphur content of wool fibres to less than half its original value by caustic soda treatment ${ }^{5}$, and that Küster and Irion had isolated a - C-S- - - derivative from the products of the action of sodium sulphide on wool ${ }^{6}$. More recently, Harris ${ }^{7}$, taking advantage of the work of Zincke and Farr ${ }^{8}$, and of Schöberl ${ }^{9}$, has shown that aldehyde groups are produced by loss of hydrogen sulphide from the sulphenic acid derived from the disulphide bond by alkaline hydrolysis, and Phillips ${ }^{10}$ has suggested that the aldehydes may condense with the basic side chains of wool to produce $-\mathrm{N}=\mathrm{CH}-$ bonds between the peptide chains.

This suggestion appears to be valid, because caustic soda-treated fibres, which fail to contract in boiling sodium bisulphite solution, contract after being subjected to treatments calculated to break $-\mathrm{N}=\mathrm{CH}-$ bonds. For example, caustic soda-treated fibres, boiled in $N / 5$ hydrochloric acid for 30 minutes, contracted 16 per cent in boiling 5 per cent sodium bisulphite solution; and treated fibres boiled in $N / 10$ pyruvic acid for 1 hour contracted 14 per cent under similar conditions ${ }^{11}$. It seems probable, therefore, that $-\mathrm{N}=\mathrm{CH}-$ bonds are present in caustic soda-treated fibres, although the incompleteness of the contraction implies that other types of bond are present, possibly the $-{ }_{1}^{\mathrm{C}}-\mathrm{S}-{ }_{1}^{\mathrm{C}}-$ bond first mentioned in this connexion.

Although Phillips makes no such suggestion in his note $^{10}$, it might be assumed that the new linkages formed in 'setting' stretched fibres in steam are
$-\mathrm{N}=\mathrm{CH}-$ in type, rather than the $-\mathrm{S}-\mathrm{NH}-$ bonds first postulated. This does not seem to be the case, because fibres set in boiling 2 per cent borax solution fail to contract in boiling $N / 5$ hydrochloric acid or $N / 10$ pyruvic acid. Not only so, but the fibres boiled in $N / 5$ hydrochloric acid retain a set even in boiling sodium bisulphite solution. Similarly, if permanent set were due to the formation of $-\mathrm{N}=\mathrm{CH}-$ bonds, the response of fibres to setting processes should be increased by pretreatment with alkalis to develop aldehyde groups. In actual fact, setting power decreases steadily with increasing time of treatment with alkali, the amount of permanent set being a linear function of sulphur content in the case of baryta-treated fibres. These and other observations, which will be described elsewhere, find a ready explanation in terms of $-\mathrm{S}-\mathrm{NH}-$ bond formation in setting processes, but no explanation in terms of the $-\mathrm{N}=\mathrm{CH}-$ bond.

\section{J. B. Speakman.}

Textile Chemistry Laboratory, University, Leeds. July 25.

1. Speakman, NATURE, 132, 930 (1933).

${ }^{2}$ Speakman, Applied Chemistry Reports, 20, 164 (1935)

${ }^{3}$ Speakman, $J$. Soc. Dyers and Colourists, Jubilee Number, 1934, p. 34 .

- Whewell, Ph.D. Thesis, University of Leeds, 1935.

${ }^{5}$ Harris, Bur. Stand. J.'Research, 15, 63 (1935).

- Küster und Irion, Z. physiol. Chem., 184, 225 (1929).

${ }^{7}$ Harris, Bur. Stand. J. Research, 16, 475 (1936).

Zincke und Farr, Annalen, 391, 57 (1912).

- Schöberl, Annalen, 507, 111 (1933).

10 Phillips, NatURE, 138, 121 (1936).

11 Fischer, Annalen, 253, 63 (1889).

\section{Effect of Dichlor-diethyl-sulphone on Brain Respiration}

Mr colleagues and $I$ have been developing recently the theory that vitamin $B_{1}$ is a specific factor in the oxidation system of pyruvic acid. In a search for substances which would inhibit specifically this action of vitamin $B_{1}$ in its relation to the pyruvate oxidase of brain, I tried ten months ago the effect of dichlor-diethyl-sulphone $\left(\mathrm{Cl}^{-} \mathrm{CH}_{2} \cdot \mathrm{CH}_{2}\right)_{2} \mathrm{~S} . \mathrm{O}_{2}$, for a specimen of which I am indebted to Dr. E. Walker. I am encouraged to communicate the results by the recent publication of Berenblum, Kendall and $\mathrm{Orr}^{1}$, who state that D.E.S. with tumour tissue inhibits respiration some 50 per cent and glycolysis some 84 per cent. I have found that the action of D.E.S. upon our brain respiration systems in vitro resembles in detail the effect of iodoacetic acid ${ }^{2}$; the significant points are as follow :

Noticeable effects upon respiration in lactate Ringer phosphate solutions are produced by so little as $0.000087 M$. (up to 50 per cent inhibition) D.E.S. With $0.000174 M$. (similar concentration for iodoacetic acid, $0 \cdot 005 M$. approx.) and our usual technique, pyruvate is not oxidized, but accumulates from normal respiring brain tissue in presence of lactate. Hence at this concentration in the reactions

$$
\begin{aligned}
& \text { D.E.S. } \\
& \text { Lactate } \underset{C}{\rightarrow} \text { Pyruvate } \underset{D}{\stackrel{\downarrow}{D} \text { oxidation products }}
\end{aligned}
$$

there is no appreciable effect upon step $C$, but only upon $D$. Lack of vitamin $\mathrm{B}_{1}$ also affects stage $D$, but as with iodoacetic acid, the action is not upon the vitamin $B_{1}$ component. Addition of excess vitamin $B_{1}$ will not restore the action with normal brain 